\title{
Massacre em Realengo: a cobertura imagética da revista Veja em ataque misógino
}

\section{Massacre in Realengo: the imagery coverage of Veja's magazine in a woman-hater attack}

\author{
Hertez Wendel de Camargo ${ }^{1}$; Renata Frigeri ${ }^{2}$
}

\section{Resumo}

Este trabalho estuda a cobertura fotográfica do massacre de Realengo, no Rio de Janeiro, quando um ex-aluno entrou em salas de aula e assassinou a tiros dez meninas e dois meninos. O estudo limita-se às fotografias publicadas pela revista Veja, veículo eleito para objeto de estudo. O objetivo deste trabalho é verificar a intencionalidade dos fotógrafos que realizaram a cobertura do ataque na construção de imagens e geração de sentidos.

Palavras-chave: Massacre de Realengo. Fotojornalismo. Revista Veja. Intencionalidade de comunicação.

\begin{abstract}
This work studies the photographic coverage by Veja magazine of the massacre of Realengo, in Rio de Janeiro, when a former student entered the classroom killed and ten girls and two boys. The study is limited to photographs published by Veja magazine, the vehicle chosen for the object of study. The objective of this work is to verify the intent of photographers covered the attack on the construction of images and senses of generating.
\end{abstract}

Key-words: Murder in Realengo. Photojournalism. Veja magazine. Of intentional communication.

\section{Introdução}

Os crimes de ódio são caracterizados pela violência dirigida a grupos determinados, seja por sexo, raça, idade, características físicas ou ideológicas. Eles diferem de um crime comum, por serem movidos pelo ódio às pessoas que, simplesmente, pertencem a determinado grupo. Além disso, eles fragilizam não apenas a vítima e suas relações fraternais e fazem todo o grupo sentirse vulnerável e exposto.

\footnotetext{
${ }^{1}$ Graduado em Comunicação Social, habilitação em Publicidade e Propaganda pela Universidade Metodista de Piracicaba; graduado em Comunicação Social, habilitação em Jornalismo, pela Faculdade União Metropolitana Londrinense; mestrado em Educação, Conhecimento, Linguagem e Arte pela Universidade Estadual de Campinas; doutorado em Estudos da Linguagem, pela Universidade Estadual de Londrina. É coordenador dos cursos de Comunicação Social (Publicidade e Propaganda e Jornalismo) da Faculdade Pitágoras de Londrina. Email: hertzwendel@yahoo.com.br

${ }^{2}$ Graduada em Comunicação Social, habilitação em Publicidade e Propaganda pela Universidade Estadual do Centro-Oeste; especialização em Práxis e Discurso Fotográfico pela Universidade Estadual de Londrina; mestranda em Comunicação Visual pela Universidade Estadual de Londrina. É professora dos cursos de Comunicação Social (Publicidade e Propaganda e Jornalismo) da Faculdade Pitágoras de Londrina. Email: renatafrigeri@yahoo.com.br
} 
No mundo todo há exemplos que marcaram a história da Humanidade: no século XX, o mais famoso crime de ódio aconteceu com a ascensão do nazismo, sob o governo de Hitler na Alemanha, que resultou em uma perseguição aos judeus, ciganos, homossexuais e deficientes físicos: mais de 6 milhões de pessoas morreram. No Brasil recente, alguns crimes movidos unicamente pelo ódio também não serão esquecidos: em julho de 1993, um ataque a crianças de rua, que dormiam sob as marquises da igreja da Candelária, no Rio de Janeiro, deixou oito mortos; em novembro e dezembro de 2010, homossexuais foram agredidos fisicamente na Avenida Paulista, em São Paulo; e em abril de 2011, um ex-aluno de uma escola pública do bairro de Realengo, no Rio de Janeiro, entrou em salas de aula de sua ex-escola e matou doze crianças, das quais dez eram meninas.

Em alguns crimes movidos unicamente pelo ódio é percebido de maneira imediata o grupo a que ele foi direcionado. Porém outros são mais difíceis de serem notados como tal, e esse é o caso do massacre em Realengo. As primeiras notícias divulgadas na imprensa diziam que o ataque era direcionado às crianças, entretanto em diversas entrevistas com os sobreviventes se elucidou que o ataque era para atingir meninas: "Suspeita-se que ele selecionou suas vítimas pelo sexo. Dez das crianças mortas eram meninas e receberam tiros característicos de execução, na cabeça e no tórax. Um grupo de cinco estudantes disse a Veja ter ouvido Wellington afirmar em meio ao massacre que não queria matar meninos." (BRASIL; DINIZ; SEGALLA, 2011, p. 84). A carta escrita pelo assassino Wellington Menezes de Oliveira também deixa indícios de sua ira ao sexo oposto. Nela, o assassino fala muito de impureza, o que denota um caráter sexual muito forte, reforçando sua perseguição às meninas.

Violência e crimes de ódio direcionados ao sexo feminino não são novidades no Brasil: segundo dados da Secretaria Especial de Políticas para as Mulheres, a cada 15 segundos uma mulher sofre algum tipo de agressão no país e um estudo feito pelo Instituto Sangari (WAISELFISZ, 2011) para mapear a violência no Brasil mostrou que, de 1998 a 2008, dez mulheres foram mortas por dia. Ao todo, 41.968 mulheres foram assassinadas.

O massacre no bairro de Realengo ocorreu na manhã do dia 07 de abril de 2011. Conforme as informações chegavam, sítios na internet e jornais televisivos divulgavam as informações, nem sempre confirmadas. Num primeiro momento, houve uma correria nos veículos para noticiar em primeira mão as informações. Posteriormente, muitas delas foram desmentidas ou ratificadas. As fotografias publicadas na Veja, tanto na edição impressa, como na edição digital, são de diferentes fotógrafos, de várias agências de notícias.

\section{A Intencionalidade e a Construção da Imagem}

Fotografias podem ser analisadas através de diferentes metodologias. Neste trabalho utilizou-se a metodologia utilizada proposta por Boni (2000), que ocorre em primeiro nível, a do próprio fotógrafo, pois ele é o emissor da mensagem e manifesta sua intencionalidade com os recursos técnicos e os elementos da linguagem fotográfica.

A fotografia constitui uma mensagem de códigos abertos e contínuos, não codificados ou convencionalmente formados. Com isso, no fotojornalismo, no qual a imagem deve informar, é inquestionável a intencionalidade de comunicação do fotógrafo, pois é ele que define a composição e os recursos técnicos que serão utilizados para transmitir determinada informação ao leitor. O repórter fotográfico trabalha com substantivos, mas utiliza-se da técnica e dos elementos da linguagem fotográfica para adicionar adjetivos à imagem. (BONI, 2000).

A composição é o recorte, o enquadramento, a seleção que será transmitida ao leitor, é um espaço temporal recortado, que dará ao receptor a sensação 
de ter testemunhado a cena. A credibilidade da imagem, segundo Sontag (2004), ocorre porque as imagens fotografadas não parecem manifestações a respeito do mundo, mas sim pedaços dele, miniaturas da realidade que qualquer um pode fazer ou adquirir. Ao escolher sua seleção, o fotógrafo elege elementos que lhe interessam e essa percepção será a contemplada por quem irá ler a imagem, portanto, sua intenção de comunicar fica clara através do recorte e é transmitida ao leitor.

Os elementos que serão priorizados na seleção são definidos por elementos técnicos da fotografia por meio das perspectivas e planos eleitos, da profundidade de campo priorizada, do foco em determinado tema, a lente mais adequada, o ângulo ou movimento escolhido para capturar a cena. Cada recurso técnico tem o poder de transmitir sensações diferentes e induz o leitor a conclusões pré-determinadas por quem concebeu a imagem. E essa fotografia é entendida pelo leitor, segundo Sousa (2000), como memória: ela serve para lembrar aquilo que aconteceu e é um espelho do real: o fotógrafo esteve ali, presenciou e registrou, a imagem fotográfica faz crer na verdade.

\section{Análise das Imagens}

A revista Veja, na edição 2212, de 13 de abril de 2011, publicou 29 fotografias referentes ao massacre de Realengo, distribuídas entre a capa e as vinte páginas de matéria a respeito do assunto, além de infográficos, imagens da carta deixada pelo assassino e fotografias do desempenho escolar do mesmo. Além da revista impressa, a Veja também fez um especial online, para dar as notícias em tempo real e não atrasar a atualização de seus leitores. Nessa edição virtual publicou dezenas de outras imagens.

Para delimitação deste estudo, foram selecionadas sete fotografias publicadas tanto na edição impressa como no especial online, de diferentes fotógrafos: Wagner Meie, Fábio Motta, Genilson Araújo, Selmy Yassuda, Marcelo Sayão, Antônio Lacerda e Sérgio Oliveira.

A imagem abaixo (Figura 1) foi registrada pelo fotógrafo Wagner Meie, após a tragédia na escola. Nela há um homem ajoelhado com a cabeça baixa; com uma das mãos ele limpa os olhos, já que possivelmente chorava; ele está diante de um muro repleto de elementos de significação: a cruz, que simboliza cada uma das crianças assassinadas, é o maior símbolo do cristianismo e remete a sofrimento e morte; as velas acesas representam a religião e a esperança; as cartas e bilhetes para uma possível comunicação com as crianças que se foram; as flores, normalmente ligadas à vida e ao amor, aqui são a despedida; e o próprio muro, que pode significar o limite, a barreira, já que não é possível ir além dele; além de um quadro cuja escrita é impossível de ler, mas que faz referência à escola. Os elementos de significação transmitem ao leitor a tragédia e a sensação de impotência do ser humano, já que mais nada pode ser feito para evitar o ocorrido. A imagem humanizada chama a atenção para as dores individuais, o elemento humano é o mais importante e também na imagem ele está impotente.

Figura 1 - Homem chora a morte dos adolescentes na tragédia que chocou o país.

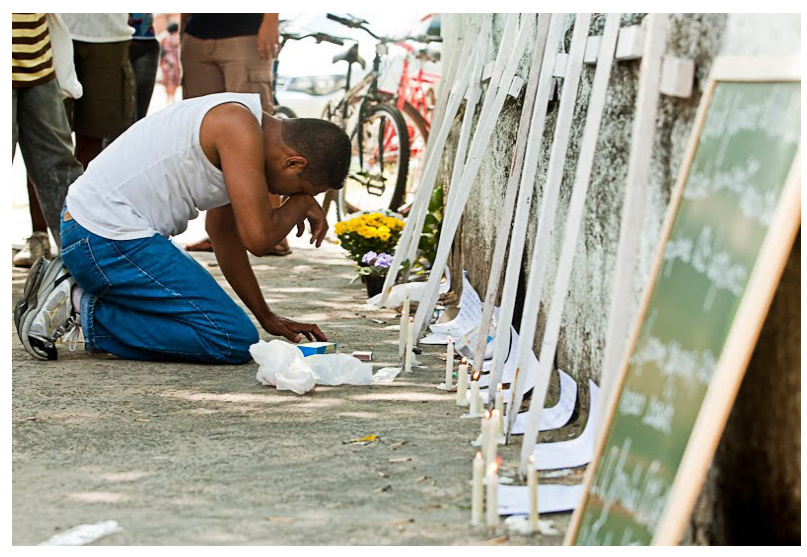

Fonte: Brasil, Diniz e Segalla (2011, p. 84).

Fotografia: Wagner Meie, Fotoarena. 
Ao compor a imagem, o fotógrafo escolheu o plano médio, para interagir o sujeito ao ambiente; provavelmente tenha usado uma teleobjetiva, para aproximar o tema sem ser notado, sem interferir na cena; usou o diafragma aberto, para destacar seu tema e desfocar o restante, não permitindo a leitura do quadro em primeiro plano, mas conduzindo o olhar do leitor justamente para o homem que chora diante do muro. O fotógrafo optou por ficar no mesmo ângulo que o fotografado, para propiciar ao leitor a sensação de testemunha, de proximidade com o tema e com a dor de cada uma das famílias.

A segunda fotografia (Figura 2) foi registrada pelo fotógrafo Fábio Motta. É um close da farda de um bombeiro suja de sangue, logo após o massacre na escola. A imagem feita em plano fechado induz o leitor a situar o personagem em questão (bombeiro) e o sangue faz o leitor pensar na tragédia. $O$ fotógrafo elegeu uma teleobjetiva para se aproximar de seu objeto fotografado e não interferir na ação, usou o diafragma completamente aberto, para destacar seu interesse e desfocar o fundo da cena, optou por uma fotografia sem nenhuma profundidade de campo, o que poderia desviar a atenção do leitor para possíveis objetos ao fundo. A imagem foi registrada mediante um plongé bastante suave, mas acima do tema.

Figura 2 - Farda de um bombeiro suja de sangue, em frente ao Hospital Albert Schweitzer, em Realengo, na zona oeste do Rio de Janeiro.

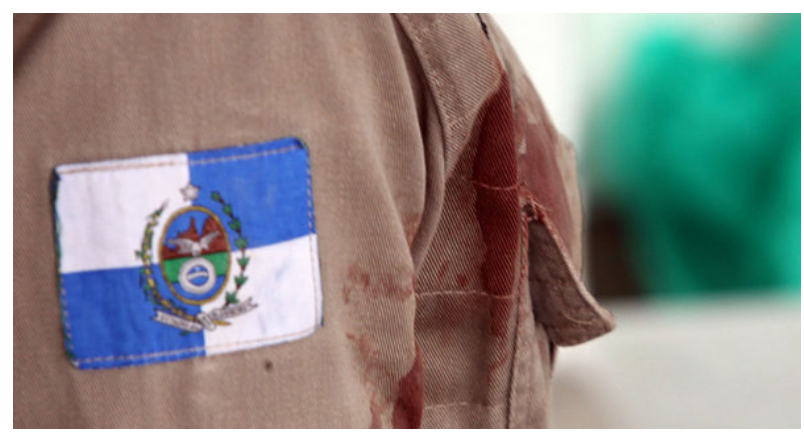

Fonte: Veja (2011b).

Fotografia: Fábio Motta/ AE.
Este bombeiro não é qualquer um, mas o que provavelmente carregou em seus braços uma criança ferida, caso contrário seria muito improvável essa mancha de sangue em seu ombro. Esta associação, na maioria das vezes, inconsciente, faz com que o leitor se sinta perturbado com a imagem, mesmo não conseguindo identificar de modo objetivo o quê o incomoda. Os elementos de significação são contrastantes, já que o bombeiro representa proteção enquanto o sangue que significaria a vida, quando derramado, remete à violência e à morte. Os elementos em contraste e fora de sua ordem natural induzem o leitor ao choque, à tristeza representada pela tragédia. Entretanto, o fundo verde pode induzir à esperança em dias melhores.

A próxima fotografia (Figura 3) é uma imagem aérea, capturada pelo fotógrafo Genilson Araújo. É uma das primeiras imagens que surgiram nas emissoras de televisão e na internet: como o tumulto ao redor da escola não permitia a aproximação da imprensa, optou-se por tentar registrar imagens aéreas para entender o que acontecia. No momento do registro da imagem, não havia informações confirmadas, sabia-se apenas que alguém atirava dentro de uma escola, mas o assassino ainda não tinha identidade conhecida.

Figura 3 - A Escola: sem saber se seus filhos estavam entre os mortos, pais se aglomeram em frente ao colégio Tasso da Silveira.

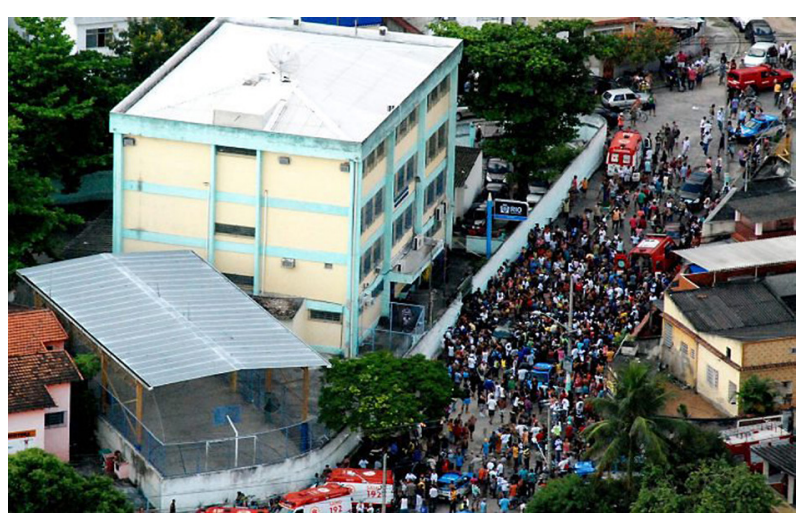

Fonte: Brasil, Diniz e Segalla (2011, p. 83).

Fotografia: Genilson Araújo / AG O Globo 
O fotógrafo optou por uma objetiva normal, para possibilitar ao leitor uma completa noção da cena do crime, e também há muita profundidade de campo, e é possível ver com detalhes todos os elementos, desde os vários carros de bombeiros às dezenas de pessoas que se aglomeram em frente ao muro da escola e todo o prédio da própria escola, incluindo a sua quadra de esportes. O uso desta lente em plano geral possibilita ao leitor a sensação de onisciência, tudo ele vê e observa, a perspectiva da imagem, num imenso ângulo plongé, permite ao leitor mergulhar na fotografia, imergir na cena. $\mathrm{O}$ leitor percebe que algo grave aconteceu por ver vários carros de bombeiros na cena e muitas pessoas aglomeradas no portão da escola; a presença de pessoas poderia remeter o leitor a muitas situações, como um show ou uma comemoração determinada, mas a presença dos carros dos bombeiros indicia o leitor do perigo eminente.
A imagem capturada pela fotógrafa Selmy Yassuda (Figura 4) é carregada de mistério, pela luz e pela grade que tomam conta de quase todo o cenário. Aqui, a fotógrafa poderia ter escolhido entrar na cena, por meio de uma teleobjetiva, e capturar as expressões dos peritos, mas preferiu manter-se como observador, em um plano médio, tal qual as pessoas próximas a ele e retratar o que alguém, sem um câmera fotográfica, veria se estivesse na sua posição. A lente utilizada, muito próxima da capacidade do olho humano, permite que a visão do leitor contemple a perspectiva criada em um ângulo normal, com boa profundidade de campo, pois é possível observar desde as grades, no começo da cena, até as janelas, no final da perspectiva. O leitor poderia entrar nessa perspectiva, não fosse a grade, que retém sua visão e sua imersão na imagem.

Figura 4 - Peritos chegam à Escola Municipal Tasso da Silveira.

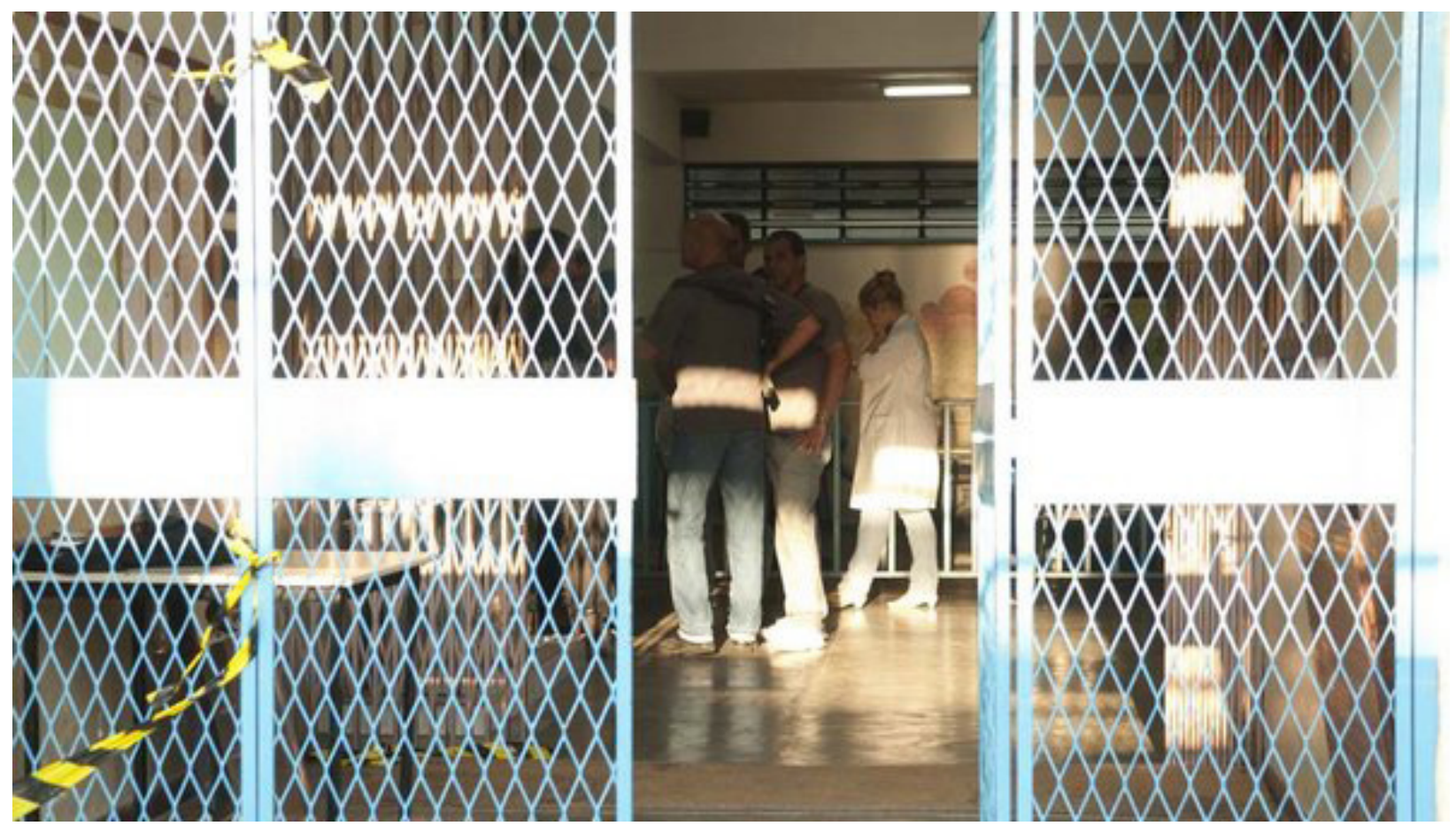

Fonte: Veja (2011a)

Fotografia: Selmy Yassuda 
Essa imagem torna o leitor um observador, mas sem consciência do que acontece naquele ambiente, carregado de tensão e mistério, pois não é possível ver o que os peritos veem. A luz que incide na tela é quase cenográfica e adentra ao ambiente reforça o mistério e aguça a curiosidade: não se sabe o que acontece ali, mas tem-se impressão de que sejam notícias ruins.

Os elementos de significação se manifestam nessa fotografia: peritos são profissionais designados para investigações de crime, portanto a sua presença ali reforça o receio e a dor; caso não houvesse mortos, a presença deles poderia ser dispensável. A grade limita a visão do leitor e a possibilidade de se obter mais informações, reforçando a atmosfera de mistério em conjunto com a luz teatral, que, de tão clara que está no primeiro plano, cega o leitor em determinados pontos. A faixa de isolamento afirma para o observador que naquele lugar ocorreu um crime, portanto, não é aconselhável a aproximação, e suas cores, amarelo e preto, remetem a perigo e atenção.

A fotografia registrada pelo fotógrafo Marcelo Sayão (Figura 5) exibe um bombeiro segurando uma criança ferida. Entretanto, ao observar a legenda, o leitor descobre que, além de ser bombeiro, o personagem é o pai da criança machucada: "O bombeiro Adriano com o seu filho Gustavo Damaceno que ficou ferido durante a chacina na Escola Municipal Tasso da Silveira.”(VEJA, 2011a).

Figura 5 - O bombeiro Adriano com o seu filho Gustavo Damaceno que ficou ferido durante a chacina na Escola Municipal Tasso da Silveira.

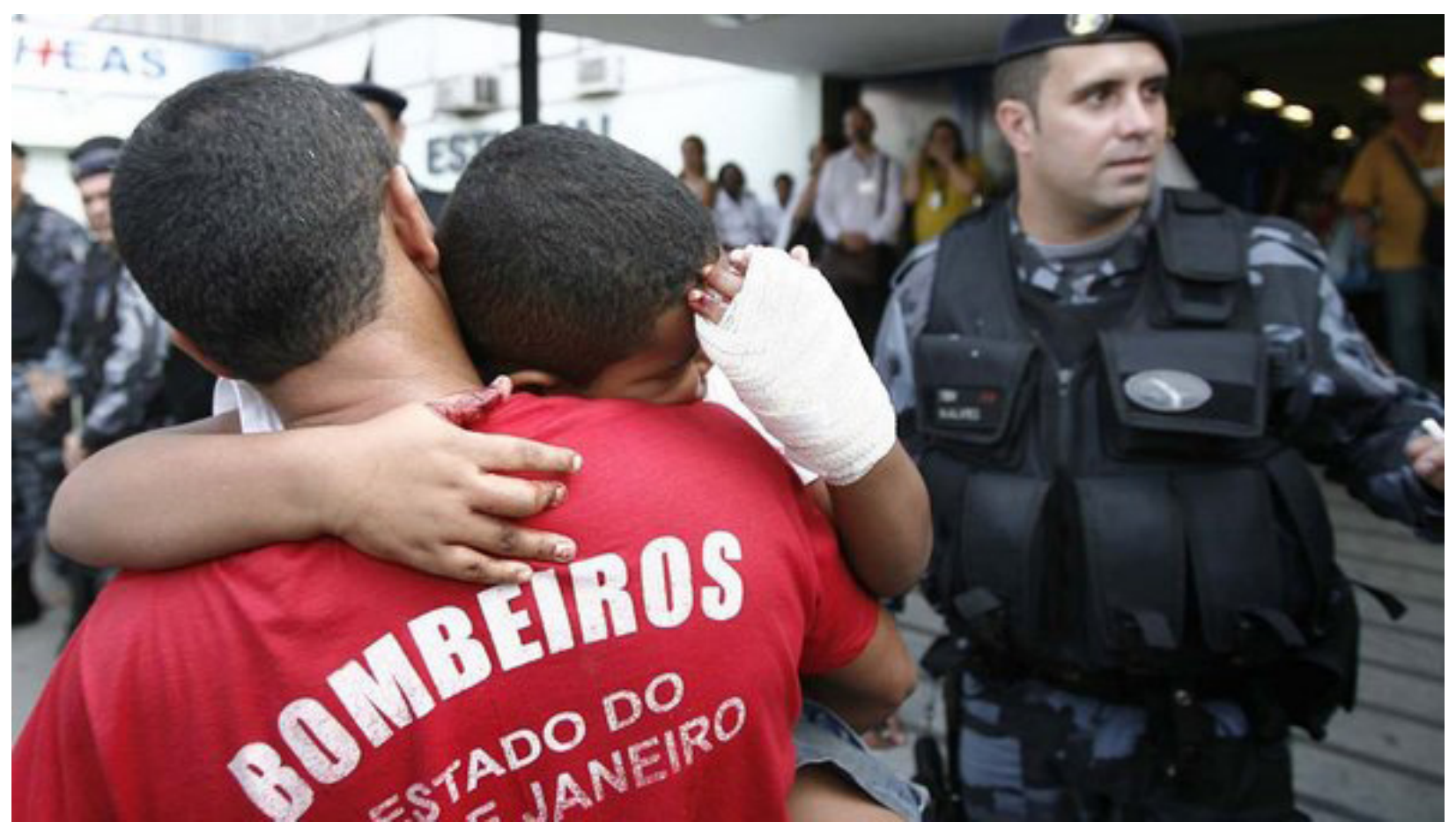

Fonte: Veja (2011a).

Fotografia: Marcelo Sayão/EFE.

A criança está visivelmente fragilizada. A mão enfaixada e os dedos sujos de sangue conotam que ela foi ferida durante o massacre. No colo do pai-bombeiro está agora em segurança, ninguém mais pode machucá-la; a identificação na camiseta do homem reforça esta proteção, posto que os 
bombeiros remetem à segurança e proteção. A fotografia mostra ao leitor a dor individualizada, o sofrimento de cada um dos personagens que estavam na escola e de seus familiares. O bombeiro Adriano e o aluno Gustavo, nesta imagem, representam individualmente o sofrimento de todos.

O fotógrafo tomou a imagem em plano americano, impossibilitando a identificação do lugar onde foi registrada. Seu objetivo, provavelmente, era manter o olhar do leitor nos personagens. Para isso, escolheu uma teleobjetiva para ganhar aproximação do assunto, sem interferir na cena ou ser notado. Também utilizou o diafragma aberto para manter o foco no primeiro plano, onde estão o pai-bombeiro e a criança machucada, perdendo gradativamente profundidade de campo. É possível identificar o policial que está próximo a eles, porém a imagem já está desfocada, no fundo da fotografia. Veem-se policiais e civis, porém não há nitidez nesses personagens, mantendo o olhar do leitor no primeiro plano.

Durante o velório de Larissa Santos, uma das dez meninas assassinadas em Realengo, o fotógrafo Antônio Lacerda registrou a imagem de uma garotinha que participava da despedida de Larissa (Figura 6). A fotografia foi tomada em plano fechado, isolando a menina de todo o ambiente; sem a legenda não há localização espacial para o leitor. A imagem não possui perspectiva ou profundidade de campo, mas sim foco seletivo, fazendo com que o olhar do observador se retenha na garota. O fotógrafo precisou agachar para não achatar a imagem e conseguir um ângulo contra-plongé muito suave, provavelmente fez uso de uma teleobjetiva, para não se aproximar da garota e permitir que ela o notasse.

Para representar o velório, o fotógrafo poderia ter criado dezenas de diferentes imagens, com diversos pontos de interesse, entretanto, isso poderia atrair a atenção do leitor para lugar nenhum. A composição simples que fez foi bastante eficaz para transmitir a sensação do que ocorria naquele lugar.
Figura 6 - Criança no velório de Larissa Santos, 13 anos, morta na Escola Municipal Tasso da Silveira.

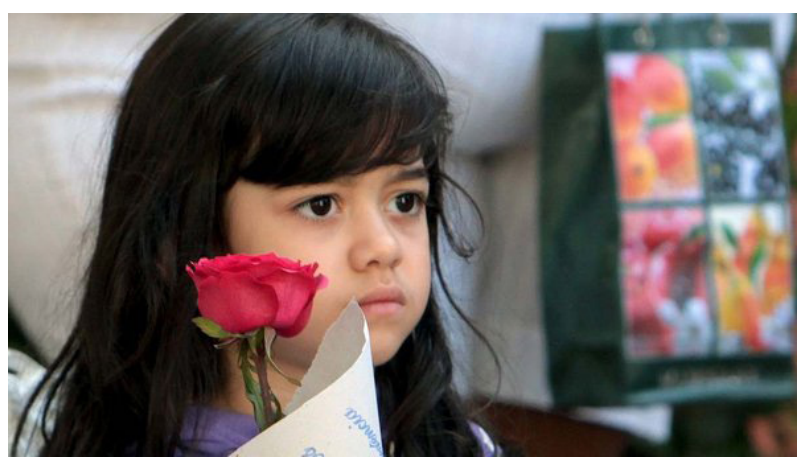

Fonte: Veja (2011c)

Fotografia: Antônio Lacerda/EFE

Apesar do olhar fixo, percebe-se que a garota carrega nele certa desorientação: ela não sabe ao certo o que aconteceu, nem o motivo da tragédia. $\mathrm{O}$ leitor não consegue ver o que ela vê, mas é possível ler tristeza em seu olhar. A sensação conotativa da imagem é de fragilidade, a rosa vermelha que ela segura, normalmente usada para representar o amor, aqui torna a imagem sensível, pois são dois elementos que circulam em torno da fragilidade: a flor e a menina.

A fotografia de Sérgio Oliveira (Figura 7), última escolhida para esta análise, possui uma forte carga de significados: mostra o assassino morto, aquele que destruiu vidas, mas também perdeu a sua. Fotografias de inimigos mortos não são novidades na imprensa e muitas foram registradas e noticiadas desde as primeiras coberturas fotográficas de guerras. Elas representam a vitória contra o inimigo, a sua derrota e impotência e servem para provar a soberania daquele grupo.

Provavelmente é a imagem que mais interessa ao leitor, pois ver a derrota de quem causou a tragédia e a dor talvez traga reconforto ao observador, às famílias e às vítimas. Na cobertura imagética realizada pela revista Veja, as imagens que mostram a morte são sempre do assassino; nas demais em que as vítimas aparecem, ora as imagens estão 
desfocadas, ora cortadas, para que não exista identificação por parte do público ou das famílias. $\mathrm{O}$ elemento de significação mais forte que se percebe na cena é a lona preta, que envolve o corpo do assassino. O leitor, com conhecimento prévio de sua utilização, sabe o que a lona esconde e isso pode causar desconforto para quem observa a fotografia.

Figura 7 - Bombeiros carregam o corpo do exaluno que cometeu suicídio após invadir a Escola Municipal Tasso da Silveira e abrir fogo contra os alunos. Ao menos 12 pessoas morreram.

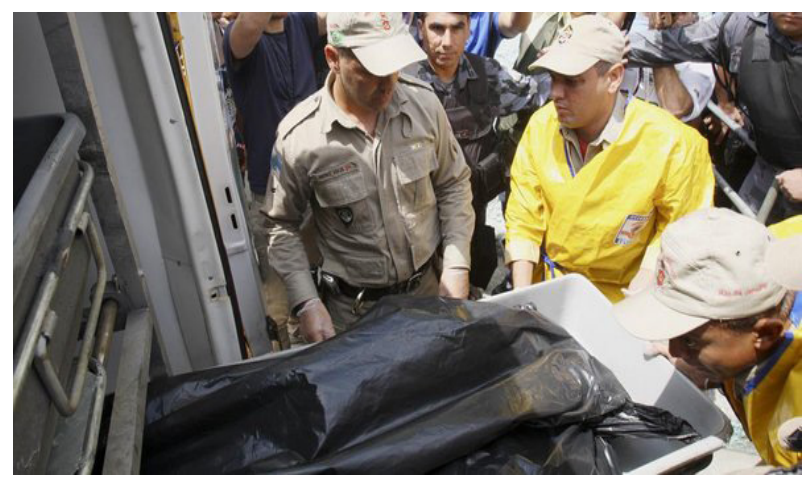

Fonte: Veja (2011c).

Fotografia: Sérgio Oliveira/AFP

Para capturar a imagem, o fotógrafo utilizou um plano médio, no qual é possível observar o que se presume ser o corpo do assassino, além dos policiais que no momento recolhem o corpo. Há profundidade de campo em toda a extensão da imagem, o que permite perceber o movimento da fotografia. Esse movimento estende o raciocínio do leitor para a continuidade da cena e o induz a ação. O ângulo plongé, bem acima do tema, coloca o leitor na sensação de mergulho: ele observa do alto, acima dos acontecimentos; é o leitor-observador, que a tudo enxerga.

\section{Considerações Finais}

A revista Veja optou por não publicar fotografias que identificassem as crianças mortas, mas sim pelas que induzissem o leitor a perceber o drama das famílias e a tensão que ocorreu naquela quintafeira, evidenciando o elemento humano, sem dúvida, o mais importante para o fotojornalismo. A publicação, tanto na edição impressa como na online, não declarou explicitamente o crime de ódio por sexo, mas induziu que este poderia ser o motivo, já que morreram mais meninas que meninos e, segundo a revista, os tiros disparados nas garotas denunciavam características claras de execução.

O fotojornalismo, segundo Sousa (2000) não faz abordagens essencialmente objetivas, sem pontos de vista ou realistas, a seleção consciente daquilo que se vai incluir numa fotografia é um passo fundamental para capturar o olhar do leitor e transmitir a informação desejada. O fotógrafo é capaz de articular aquilo que deseja mostrar, por intermédio das ferramentas próprias da fotografia que lhe são disponíveis: são recursos técnicos e os recursos da linguagem fotográfica, que podem reforçar, selecionar, destacar ou mostrar ao leitor o que acontece naquele lugar.

A partir da análise das imagens selecionadas, nota-se que as fotografias publicadas pela Veja dão ao leitor uma dimensão da tragédia que assolou o país. Evidenciando a intencionalidade dos fotógrafos ao fazer a cobertura midiática da tragédia em Realengo, a edição faz com que o leitor percorra e perceba todos os cenários do evento, possibilitando a ele uma noção clara dos fatos ocorridos. É possível afirmar que as fotografias referentes ao massacre serão mais fixadas na mente se comparadas com as imagens em movimento (vídeos), já que de acordo com Sontag (2004), elas são uma nítida fatia do tempo e não um fluxo, portanto, se tornam mais memoráveis ao observador.

Portanto, pode-se confirmar a intencionalidade dos fotógrafos durante a construção das fotografias, como proposto por Boni (2000), pois as imagens 
foram construídas para informar aquilo que o fotógrafo presenciou, ele traduziu ao leitor suas percepções em imagens, lançando mão de seus recursos técnicos e de elementos da linguagem fotográfica para gerar sentidos, para auxiliar, facilitar ou mesmo induzir o leitor à leitura desejada.

\section{Referências}

BONI, P. C. O discurso fotográfico: a intencionalidade de comunicação no fotojornalismo. São Paulo. 2000. Tese (Doutorado em Ciências da Comunicação) - Universidade de São Paulo, São Paulo. 2000.

BRASIL, S.; DINIZ, L.; SEGALLA, V. Cruel, aterrador e inexplicável. Veja, São Paulo, ano 44, n. 15, p. 80-100, abr. 2011.

WAISELFISZ, J. J. Mapa da violência 2011: homicídios de mulheres no Brasil. São Paulo: Instituto Sangari, 2011. Disponível em: $<$ http:// www.sangari.com/mapadaviolencia/pdf2011/ homicidio_mulheres.pdf $>$. Acesso em: 10 jun. 2011.

SONTAG, S. Sobre fotografia. Tradução de Rubens Figueiredo. São Paulo: Companhia das Letras, 2004.

SOUSA, J. P. Uma história crítica do fotojornalismo ocidental. Florianópolis: Letras Contemporâneas, 2000.

VEJA. A dor dos familiares e a indignação dos moradores de Realengo. 2011a. Disponível em: $<$ http://veja.abril.com.br/multimidia/galeriafotos/a-dor-dos-familiares-e-a-indignacao-dosmoradores-de-realengo $>$. Acesso em: 20 jun. 2011.

VEJA. Massacre em Realengo. 2011b. Disponível em: <http://veja.abril.com.br/tema/massacre-emrealengo $>$. Acesso em: 20 jun. 2011.

VEJA. Velório das vítimas do massacre em Realengo. 2011c. Disponível em: <http://veja. abril.com.br/multimidia/galeria-fotos/velorio-dasvitimas-do-massacre-em-realengo $>$. Acesso em: 20 jun. 2011.

Recebido em: ago. 2011 Aceito em: dez. 2011. 
